\title{
Social Media Networks And SME Performance In The International Arena: A Case Of SMEs Operating In Kamukunji Area of Nairobi County, Kenya
}

\author{
Judy Wanyoike and Peter Paul Kithae
}

\begin{abstract}
The Internet has significantly changed the world and so has social media. Social media has offered a free for all stage for using social network and friends to create awareness and SMEs can leverage on this and advance their business in the international arena. The general objective of the study was to analyze the effect of social media networks on SME performance in the International Arena, with special focus on those operating in Kamukunji area of Nairobi County, Kenya. The study aimed to achieve the following specific objectives; to assess the influence of use of social media networks in customer relations on SMEs Performance in the International Arena and to analyze the influence of use of social media networks while sourcing for inputs on SMEs Performance in the International Arena. Theories underpinning this study included Social Exchange Theory and Social Penetration Theory. The study employed a descriptive research design. The target population of this study comprised of 838 SME firms operating at Kamukunji in Nairobi County and considered $10 \%$ of the population. Questionnaires were used to obtain important information about the population. Data collected was both quantitative and qualitative in nature. Analysis was done quantitatively and qualitatively by use of descriptive statistics. This included percentages, mean and standard deviation which were presented using tables and charts to give a clear picture of the research findings. Results showed that social media platforms have the potential to promote customer relations as well as to source for inputs. Utilization of social media platforms enhances SMEs performance in the International Arena to a great extent. The study concluded that customer relations and sourcing for inputs all have significant effects on SMEs performance in the International Arena. The study recommended that in order to promote SMEs performance in global arena, SMEs must invest in building stronger customer relationships especially through utilization of social media platforms. Further SMEs should seek to learn and adopt social media tools that provide an opportunity for growth of the business through increased sales, profits and providing employment for Kenyans.

Index Terms-Small and Medium Enterprises, social media networks, Performance in International Arena
\end{abstract}

\section{INTRODUCTION}

Social media are forms of electronic communication through which people create online communities to share information, ideas and personal messages (Haenlein, 2016). Social networking is the practice of expanding the number

Published on October 30, 2019

Judy Wanyoike, The Management University of Africa, Kenya. (e-mail: judywanyoike3@gmail.com).

Peter Paul Kithae, The Management University of Africa, Kenya.

(e-mail: pkithae@mua.ac.ke). of one's business and/or social contacts by making connections through individuals, often through social media

sites such as Facebook, Twitter, LinkedIn WhatsApp and Google. This study will analyse how social media helps SMEs at Kamukunji market penetrate the international markets. Kamukunji lies in the eastern side of the city of Nairobi, the capital city of Kenya, and is the home to many micro-enterprises dealing with different products.

From a global perspective, many big co-operations have been using social media to penetrate other markets and they have seen how it has big impact to their brands. A company like Ford has used social media networks to create rings about the Ford Fiesta where they did their online campaign months before the event released in the US market. The posted video on YouTube alone got 6.5 million views which resulted to over 50,000 information requests from non-Ford drivers. This enabled Ford to sell 10,000 cars in six days. Similarly, Dell has used social media to learn from its customers what their needs are and had adopted not less than 500 ideas out of 17,000 ideas from its customers (Koroma, 2017).

At the regional level, Jagongo (2018) revealed that the social media in South Africa and Ghana offered huge market access, which resulted in the significant return on investment (ROI) for small businesses. Khan and Karodia (2016) revealed a high rate of positive response about the usefulness of social media from respondents in Nigeria where $51 \%$ of these brands agreed that Facebook was an effective channel for marketing, $70 \%$ of respondents agreed that the platform was useful for public relations, $62 \%$ of the respondents suggested it was useful for marketing, and $43 \%$ agreed that it was useful for customer relations. In Kenya, small businesses contribute substantively in the economy of the country especially in Nairobi. An increase in customer accessibility among these business results to an increase in profit, and it is through social media that these businesses can expand their marketing.

\section{A. Small and Medium Enterprises in Kenya}

Small and Medium Enterprise (SME) refers to a business whose sales turnover or the number of full time staff falls below a certain limit. The exact thresholds vary from country to country. As per the description of the Micro and Small Enterprise Act, 2012, firms are considered small when they have a turnover not exceeding 5 million and have between 11 and 50 employees. Micro-enterprises are those that have 1-10 employees and their 6 turnovers do not exceed 500,000 Kenyan shillings. The sector has grown 
rapidly in the last decade and has been a huge boost to the economy. A large driving force to the sector has been the banking sector (World Bank, 2015).

The growth of the sector has also created a lot of job opportunities for the youth, in both the formal and informal sector. Innovation is also a major driver in economic development, and SMEs are at its forefront of it. Just like in many other developing countries, SMEs in Kenya are the leading in innovation, science, and in business strategies (Olonde, 2017). These innovative ideas foster development by creating new opportunities. This ultimately leads to creation of employment, and increase in business returns. Compared to other corporations, SMEs often have very little financing. Their capital base is not as wide as that of established companies. Most of them are start-ups in the intensive phase of business growth and are struggling to keep up with capital needs.

Douglas (2016), in a study on the success factors for SMEs, found out that financing is a major limitation to their growth. In fact, most of the SMEs rely heavily on credit for financing. They are therefore limited from carrying out a lot of their businesses, including marketing, in the traditional manner. Given the financial constraints of SMEs, it is quite hard for them to use classic marketing techniques such as radio, $\mathrm{TV}$, and print ads, or road show campaigns. They have to opt for cheaper methods that can expand their customer base without draining their bank accounts. Social media is so far the best option for them. According to a survey by the Central Bank of Kenya, SMEs contribute to $98 \%$ of all businesses in Kenya. This is because the Kenyan economy is dominated by small informal businesses which have been growing rapidly in the past several years (Central Bank of Kenya, 2017).

\section{B. Statement of the Problem}

Despite the internet having significantly changed the world over and being available to all businesses, SMEs included, available research reports reveal that over $75 \%$ of SMES fail to survive beyond three years after start up (Kithae et al; 2015). Social media has offered a free for all stage for using social network and friends to create awareness and SMEs can leverage on this and advance their business in the international arena (Stelzner, 2015); and almost all successful businesses have been using social media to target their potential customers and increase customer awareness of their brand. However, Vij and James (2014) contend that numerous SMEs in Africa don't comprehend the effect and the possibilities of utilizing social media, and therefore continue to depend on traditional media to speak with their audience.

In Kenya, Kabue (2013) explored the elements affecting adoption of web-based social network advertising on development of SMEs in Nairobi County. The study concluded that there is a positive relationship between advertising techniques adoption and corporate performance of the firms. Likewise, Kabue (2013) study discovered that a large portion of the respondents have access to web and therefore can make a tremendous presence in web-based social networking destinations with less consideration regarding undertaking on the web advertising. This study therefore analyzed the effects of social media networks on SME performance in the international arena.

\section{Research Objectives}

The general objective of the study was to analyze the effect of social media networks on SME performance in the International Arena, with special focus on SMEs operating in Kamukunji Area of Nairobi County, Kenya; while specific objectives were to assess the influence of use of social media networks to enhance customer relations for SMEs Performance in the International Arena and to analyze the influence of use of social media networks while sourcing for inputs on SMEs Performance in the International Arena.

\section{Significant of the study}

This study will be important to all existing firms linked to the social media in Kenya as it may assist them to put in place effective networking instruments for customer relations as well as to enable players to develop and sustain performance in a changing environment. The study will also be significant to the government agencies and policy makers who may use the results to formulate positive National Policies based on a framework that is relevant and sensitive to the forces influencing business performance. Finally, future researchers can use the study as a reference point if one is researching on related topics.

This study was limited to the influence of Social Media Networks on SMEs Performance in the International Arena. Its scope entailed business owners and employee's ideas and opinions on the value they got by using social media networks within the three months of from March to August 2019.

\section{E. Operational Definition of Terms}

Customer relationship management is defined as different activities undertaken to implement company's strategies to manage the customer relationship and ensure organization's profitability.

Digital marketing is the process of building and maintaining customer relationships through

Online social networks are social networking websites, blogs or virtual worlds for socializing, information exchange and like-minded conversation.

several digital channels such as websites, email, TV, etc. to facilitate the exchange rate of ideas, products and services.

Social media marketing is the utilization of social media technologies, channels and software to create, communicate, deliver, and exchange offerings that have value for an organization' stakeholders.

\section{THEORETICAL FRAMEWORK AND INFORMING LITERATURE REVIEW}

Social Media Networks may be looked at in terms of the social penetration theory propagated by Altman \& Taylor, (1973). According to Altman \& Taylor (1973), social penetration theory provides a name for the super common phenomenon called getting to know someone. This theory posits that interpersonal relationships move from a very shallow, surface level to deeper, more intimate levels over time. Moving between the levels and getting to know someone better happens with mutual self-disclosure, or sharing inner feelings, and vulnerability, which is also, 
incidentally, sharing inner feelings. This theory assumes that self-disclosure is mutual, systematic, and predictable. It describes the role of disclosure in relationship development, focusing specifically on how self-disclosure functions in developing relationships. The onion model serves as a framework for describing the process of social penetration. In developing relationships, people use self-disclosure to increase intimacy including through breadth, depth, and the norm of reciprocity. Social penetration progresses through several stages to develop relationships (Emerson, 2016). The theory also incorporates rewards and costs in relation to social penetration and has influenced the development of a number of theories in relationship development and information management. Social Penetration theory is known as an objective theory, meaning that the theory is not subjective by personal feelings or bias. The theory is based solely on facts instead of opinions. According to this theory, penetration is rapid at the start but slows down quickly as the tightly wrapped inner layers are reached (Blau, 2014).

Since its development, this theory has proven to be versatile, allowing students and scholars of communication to employ it in many ways. However, this theory is critiqued on two accounts. First, it is first given a positive critique for its Heurism. Has led to many studies on a wide variety of relationships, and is given credit for much of thinking behind relationship development. On the other hand, the social penetration theory is often criticized for having a narrow scope and critics suggest that the process in which relationships develop are not always linear. Social penetration theory is a useful theory when trying to understand the interactions that we face every day as it looks at all of the different stages of relationships and helps us understand how we rationalize and make decisions about them.

From empirical studies, the use of social media has recently gained rapid prominence among businesses as in many other areas (Icha \& Agwu, 2015). Social media uses have been considered useful as it helps to increase customer base, enhance efficiency and effectiveness, and helping organization in partnership building with other organizations (Braskov, 2016). Moreover, Social media networks increase exposure and traffic, creates business and consumer relationships, enhances connectivity and it is a very effective mobilization tool (Eltantawy \& Wiest, 2015). There are several social media platforms, but studies indicate Facebook as the leading in the World. In 2016, for example, Facebook had more than 1.59 billion monthly active users, and it was estimated that more than 1 million small and medium-sized businesses used Facebook to advertise their business (Maina, 2016).

Other popular social media platforms are YouTube, Twitter, WhatsApp, LinkedIn, Instagram, Google+ and Tumblr. In Tanzania Facebook was also leading in 2016 with 3,700,000 subscribers (InternetWordStats, 2016). Many global corporate companies are increasingly using social media especially Facebook and Twitter to markets their products to their customers (Blau, 2014).

Researchers do adopt different approaches from time to time depending on the nature of data available, respondents, business size and industry they operate. However, the most common indicators that can be used to measure organizational performance are Return on Assets (ROA), return on equity (ROE), and profit margin (Galbraith \& Scendel, 2016). Other performance measures are sales level, sales growth rate, cash flow, gross profit margin, return on investment and retained earnings (Kilonzo, 2017), sales volumes, number of employees and net income (Wanjiru, 2013).

Notwithstanding the glowing benefits of social media for small businesses, there are obstacles to their optimal utilization. Some of these obstacles pertain to lack of ability and time to use the platform (Werees 2015). Other obstacles include the lack of knowledge of what is appropriate for clients in terms of posts. For instance, Koshy (2016) reported that failing to transmit 'culturally' correct material on the internet could lead to drastic consequences by the United Arab Emirates government. The implication of a condition such as this is that businesses have to invest ample time to understand their clients so as not to offend them by posting inappropriate material. In Thailand, Kanchanatanee (2014) found that the attitudes of the small business manager, and the compatibility and perceived usefulness of social media marketing, are probably some of the factors that can prevent small businesses from adopting emarketing.

In a related study in South Africa, Khan and Karodia (2016) revealed a high rate of positive response about the usefulness of social media from respondents: $51 \%$ of these brands agreed that Facebook was an effective channel for marketing, $70 \%$ of respondents agreed that the platform was useful for public relations, $62 \%$ of the respondents suggested it was useful for marketing, and $43 \%$ agreed that it was useful for customer relations. A study in South Africa by Ndlodo and Dhurup (2015) found that the factors which could inhibit small businesses from using electronic marketing include, amongst others, a lack of knowledge about the capabilities the platform could offer, technology incompatibility with the target audience, the stakeholder not being ready to use social media technology, a lack of orientation to, and misperception of social media.

In Kenya, a recent study by Waithaka, Muturi and Nyabuto (2014) found Facebook and Twitter to have impacted small businesses by improving communication between owners/managers and customers. According to Waithaka et al, the platforms were financially more cost effective than other media. Another study in Kenya Kimani (2014) on the use and effect of social media for the growth of small business, confirmed that Facebook and Twitter had the most users among small businesses. Their study also showed that social media was a good way to share information among different social classes. The platform created product awareness, which could be used to track client experience and more active communication. However, they suggested that the combination of both traditional and social media could gain a wide selection of customers. In addition, Jagongo (2013) found that the social media offered huge market access, which resulted in the significant return on investment (ROI) for small businesses.

\section{RESEARCH METHODOLOGY}

The study employed a descriptive research design for it portrays an accurate profile of situations (Cooper \& Schindler, 2014). The target population of this study comprised of 838 SMEs firms operating at Kamukunji in Nairobi County. The study adopted a stratified random sampling technique to select $10 \%$ of the target population (84) as respondents. According to Cooper and Schindler (2011) a representative sample is one which is at least $10 \%$ 
of the population, and according to Robson (2012), sampling is important as it saves on expenses and time that could have been used in studying the entire population (Robson, 2012). Table 3.1 shows how the sample of 84 respondents was arrived at.

\begin{tabular}{lccc}
\hline \multicolumn{4}{c}{ TABLE I: SAMPLE SIZE } \\
\hline SMEs & Population & $\begin{array}{c}\text { Sample } \\
\text { ratio }\end{array}$ & Sample \\
\hline $\begin{array}{l}\text { Beauty shops and } \\
\text { boutiques }\end{array}$ & 284 & 0.1 & 28 \\
$\begin{array}{l}\text { Electronics and } \\
\text { accessories }\end{array}$ & 167 & 0.1 & 17 \\
Kitchen utensils & 79 & 0.1 & 8 \\
General merchandise & 154 & 0.1 & 15 \\
Shoes and foot-wares & 87 & 0.1 & 9 \\
Catering firms & 67 & 0.1 & 7 \\
\hline Total & $\mathbf{8 3 8}$ & $\mathbf{0 . 1}$ & $\mathbf{8 4}$ \\
\hline
\end{tabular}

Questionnaires with both open and closed ended questions were used to obtain primary information about the population. According to Sproul (2015), a self-administered questionnaire is the only way to elicit self-report on people's opinion, attitudes, beliefs and values. The study questionnaires were developed by the researcher based on the study objectives. The researcher did a pilot test of the questionnaire to test the validity and reliability of the questionnaire. A small number of 15 respondents from the shops were used to fine tune the questionnaire to ensure that it collects the required data to answer the specific questions to solve the research problem. Isaac (2012), states that a sample size of between 10 and 30 respondents for a pilot study is adequate for any study. This helped in ensuring the questionnaire is free from errors or ambiguity.

The researcher computed a Cronbach alpha score of the instrument used to obtain the primary data. Cronbach alpha ranges between 0-1. Scores between 0-0.6 indicate that the instrument has a low reliability while scores of 0.7 and above indicate that the instrument has a high level of internal consistency and reliability (Cooper \& Schindler, 2013)

Quantitative data (collected through the closed ended questions) was used to quantify the problem by way of generating numerical data to quantify attitudes, opinions, behaviors, and other defined variables. It was also analyzed using Multiple Linear Regression Model whose general form of the Multiple Linear Regression Model is $Y=\beta_{0}+$ $\beta_{1} X_{1}+\beta_{2} X_{2}+e$

Where,

Y: the independent variable (SMEs Performance in the International Arena) expressed as a linear combination of independent variables $\mathrm{X}_{1}$ and $\mathrm{X}_{2}$ $\mathrm{X}_{\mathrm{k}}=0$

$\beta_{0}$ : The regression constant i.e. $Y=\beta_{0}$ when $X_{1}, X_{2} \ldots$.

$\beta_{1}$ : Coefficient of customer relations (independent variable $\mathrm{X}_{1}$ )

$\beta_{2}$ : Coefficient of sourcing for inputs (independent variable $\mathrm{X}_{2}$ )

\section{e: Error term}

Linear regression analysis was used to estimate the coefficients of a linear equation and the Independent variables that best predict the value of the dependent variable. From this model, test of significance at 5\% significant level was conducted on the various variables of this study using coefficient of determination $\left(\mathrm{R}^{2}\right)$, correlation coefficient (R), F-test and ANOVA table in order to check the significant of the data analyzed. A correlation analyses was carried to establish the relationship between the dependent and the independent variables.

\section{RESEARCH FINDINGS AND DISCUSSIONS}

Out of 84-targeted respondents 72 respondents filled-in and returned the questionnaires that make a response rate of $85.7 \%$. Mugenda (2003) states that a $50 \%$ response rate is adequate, $60 \%$ is good and above $70 \%$ is rated very well. The response rate was therefore rated very good. On respondent's distribution by Gender the results indicated that majority of the respondents $(62.5 \%)$ were males whereas $37.5 \%$ of the respondents were female. This implies that this study established a fair involvement of male and female respondents. However, it was evident that most of the SMEs located in Kamukunji zone were operated by male gender, these calls for investigation to establish the cause of low involvement of women in business particularly in this area. Concerning academic level of respondents, the study results that most of the respondents $(43.1 \%)$ held diploma certificate, $36.1 \%$ had certificate or trade, $13.9 \%$ had $1^{\text {st }}$ degree while $6.9 \%$ had masters. This implies that most owners of SMEs located in Kamukunji zone held college diploma certificate.

\section{A. Findings according to the research objectives}

The study sought to establish the various social media tools that SMEs operating in Kamukunji area were utilizing; where the same are analyzed as in table 4.1 below

TABLE II: SOCIAL MEDIA TOOLS USED BY SMES

\begin{tabular}{lc}
\hline Social Media tools & Percentage \\
\hline Micro blogging (i.e. Twitter) & $61 \%$ \\
Social Networking (Facebook, LinkedIn) & $88 \%$ \\
Video Sharing (i.e. YouTube) & $52 \%$ \\
Live casting (i.e. Ustream.tv, Skype) & $40 \%$ \\
Photo Sharing (i.e. Flickr) & $44 \%$ \\
\hline
\end{tabular}

The study revealed that the most commonly used social network platforms were Facebook, and LinkedIn 88\%, followed by micro blogging (i.e. twitter $61 \%$ ) video sharing (i.e. YouTube) $52 \%$ then photo sharing (i.e. flickr) $44 \%$ and lastly live casting (i.e. ustream.tv, skype) $40 \%$ in that order. According to Hubspot (2015), 57\% of small and medium businesses say social media like twitter is beneficial to their business by improving the brand

\section{B. Customer Relations}

Participants were required to indicate the extent to which the business uses social media networks to carry out each of the customer relation aspects. From the results, majority of the respondents agreed that use of social media 
networks enhanced customer bonding activities (mean = 4.27) and that through social media, SMEs are using applications such as text messaging, email and data transfer (mean $=4.20)$. These findings go hand in hand with the study findings by McGowan and McKeown (2013) that social networking can be an excellent way to acquire new customers and retain existing ones. The study also revealed that Social networking services used by SMEs operating in Kamukunji area focus on building online communities of people who share interests or activities or who are interested in exploring the interests and activities of others. Social applications enable the extension of relationships between a brand, product, or service to the individual level by providing very specific.

\section{Sourcing for Inputs}

On sourcing for inputs, the study results indicated that majority of the respondents agreed that SMEs operating in Kamukunji were sourcing for high quality materials with the use of social media (mean $=4.10$ ); and that social media facilitated effective sourcing of inputs even out of the country (mean $=4.05)$. These findings go hand in hand with the study findings by Mangold and Faulds (2016) who stated that social media marketing such as Facebook enables companies to achieve a better understanding and consideration of customer needs hence build effective relationships.

Further the study revealed that SMEs operational cost have reduced due to access to affordable raw materials $($ mean $=3.94)$ and that social media has enabled our firm to access many service providers (mean $=3.87$ ). These findings concur with the study findings by Safko \& Brake (2016) social media as online applications, platforms and media, which aim to facilitate interaction, collaboration, and the sharing of content. Nowadays, Facebook and other Social Networks are becoming increasingly important in consumers purchasing decisions. The study also revealed that social networking site that allows SMEs operating in Kamukunji zone to have conversations with suppliers, post photos and videos, promote special offers, and more, as well as 'micro-blogging' service that allows SMEs to send and receive short messages from supplies and potential bidders were highly used. These findings concur with research by Eyrich, (2008) that social media is key in promoting supplier relationship management. The results also concur with Akeem, (2017) that cost control has a positive impact on organizational performance and that the style of management has a positive impact on organizational performance. As a result of adopting social media in conducting business, customers can search for products or services depending on their affordability and availability.

\section{4.8 Inferential Statistics}

The table below displays the summary of correlation test analysis between the dependent variable (SMEs Performance in the International Arena) and the independent variables (customer relations, and sourcing for inputs).

TABLE III: CORRELATIONS

\begin{tabular}{|c|c|c|c|c|}
\hline & & $\begin{array}{c}\text { SMEs } \\
\text { Performance in } \\
\text { the International } \\
\text { Arena } \\
\end{array}$ & $\begin{array}{l}\text { Customer } \\
\text { relations }\end{array}$ & $\begin{array}{l}\text { Sourcing } \\
\text { for inputs }\end{array}$ \\
\hline \multirow{3}{*}{$\begin{array}{l}\text { SMEs } \\
\text { Performance in } \\
\text { the Internationa } \\
\text { Arena }\end{array}$} & $\begin{array}{l}\text { Correlation } \\
\text { Coefficient }\end{array}$ & 1 & $.534^{* *}$ & $.635^{* *}$ \\
\hline & $\begin{array}{l}\text { Sig. }(1- \\
1 \text { tailed })\end{array}$ & & .000 & .000 \\
\hline & $\mathrm{N}$ & 72 & 712 & 72 \\
\hline \multirow{3}{*}{$\begin{array}{l}\text { Customer } \\
\text { relations }\end{array}$} & $\begin{array}{l}\text { Correlation } \\
\text { Coefficient }\end{array}$ & $.534^{* *}$ & 1 & -.047 \\
\hline & $\begin{array}{l}\text { Sig. (1- } \\
\text { tailed) }\end{array}$ & .000 & & .229 \\
\hline & $\mathrm{N}$ & 72 & 72 & 72 \\
\hline \multirow{3}{*}{$\begin{array}{l}\text { Sourcing for } \\
\text { inputs }\end{array}$} & $\begin{array}{l}\text { Correlation } \\
\text { Coefficient }\end{array}$ & $.635^{* *}$ & -.047 & 1 \\
\hline & $\begin{array}{l}\text { Sig. (1- } \\
\text { tailed) }\end{array}$ & .000 & .229 & \\
\hline & $\mathrm{N}$ & 72 & 72 & 72 \\
\hline
\end{tabular}

From the table 4.2 , the study found that there was strong positive correlation coefficient between SMEs Performance in the international arena and customer relations, as shown by correlation factor of 0.534 , this strong relationship was found to be statistically significant as the significant value was 0.000 which is less than 0.05 . The findings concur with Franks and Curswoth, (2013) who found out that strong positive correlation between Customer relations and SMEs Performance

The study also found a strong positive correlation between SMEs Performance in the International Arena rate and sourcing for inputs as shown by correlation coefficient of 0.635 , the significant value was 0.000 which is less than 0.05 , These findings concur with the study findings by Njoroge (2011) who contents that in order to achieve the expected business performance outcomes, quality material sourcing strategies must be available.

In this study, a multiple regression analysis was conducted to test the influence among predictor variables. The research used statistical package for social sciences (SPSS V 23.0) to code, enter and compute the measurements of the multiple regressions. The model summary are presented in the table below

TABLE IV: MODEL SUMMARY

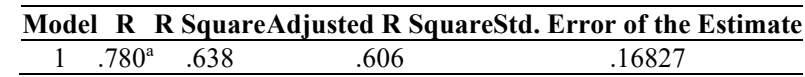

The study used coefficient of determination to evaluate the model fit. The adjusted $\mathrm{R}^{2}$, also called the coefficient of multiple determinations, is the percent of the variance in the dependent explained uniquely or jointly by the independent variables. The model had an average adjusted coefficient of determination $\left(\mathrm{R}^{2}\right)$ of 0.606 and which implied that $60.6 \%$ of the variations in SMEs Performance in the International Arena are explained by the independent variables under study (customer relations, and sourcing for inputs). The results are in line with Parveen (2016) who showed that social media usage has a very strong positive impact on organizations performance, in terms of cost reduction, improved customer relations, and enhanced information accessibility.

The study further tested the significance of the model by use of ANOVA technique. The findings are tabulated in table 4.4 below.

TABLE V: SUMMARY OF ONE-WAY ANOVA RESULTS 


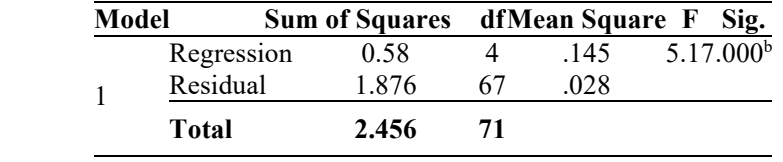

Critical value $=2.50$

From the ANOVA statics, the study established the regression model had a significance level of $0.00 \%$ which is an indication that the data was ideal for making a conclusion on the population parameters as the value of significance ( $\mathrm{p}$-value) was less than $5 \%$. The calculated value was greater than the critical value $(2.50>5.17)$ an indication that customer relations and sourcing for inputs all have a significant effect on SMEs Performance in the International Arena. The significance value was less than 0.05 indicating that the model was significant. The results are in agreement with Shavazi, Moshabaki (2013) that social media use is associated with organizational performance of a firm.

In addition, the study used the coefficient table to determine the study model. The findings are presented in the table 4.5 below.

TABLE VI: COEFFICIENTS

\begin{tabular}{lccccc}
\hline Model & $\begin{array}{c}\text { Unstandardized } \\
\text { Coefficients }\end{array}$ & $\begin{array}{c}\text { Standardized } \\
\text { Coefficients }\end{array}$ & T & Sig. \\
\cline { 2 - 4 } & $\mathbf{B}$ & $\begin{array}{c}\text { Std. } \\
\text { Error }\end{array}$ & Beta & \\
\hline $\begin{array}{l}\text { Constant) } \\
\begin{array}{l}\text { Customer } \\
\text { relations }\left(\mathrm{X}_{1}\right)\end{array}\end{array}$ & .133 & .113 & & 10.022 .000 \\
$\begin{array}{l}\text { Sourcing for inputs } \\
\left(\mathrm{X}_{2}\right)\end{array}$ & .740 & .045 & .424 & 16.280 .000 \\
\hline
\end{tabular}

As per the SPSS generated output as presented in table

above, the equation $\left(\mathbf{Y}=\boldsymbol{\beta}_{\mathbf{0}}+\boldsymbol{\beta}_{1} \mathbf{X}_{\mathbf{1}}+\boldsymbol{\beta}_{\mathbf{2}} \mathbf{X}_{\mathbf{2}}+\boldsymbol{\varepsilon}\right)$ becomes:

\section{$\mathrm{Y}=1.133+0.740 \mathrm{X}_{1}+0.428 \mathrm{X}_{2}$}

From the regression model obtained above, a unit change in customer relations holding the other factors constant would lead to a change in SMEs performance in the International Arena by a factor of 0.740 ; a unit change in utilization of social media platforms in sourcing for inputs while holding the other factors constant would also lead to a change in SMEs performance in the International Arena by a factor of 0.428 , The criteria for comparing whether the predictor variables were significant in the model was through comparing the obtained probability value and $\alpha=0.05$. If the probability value was less than $\alpha$, then the predictor variable was significant otherwise it wasn't. All the predictor variables were significant in the model as their probability values were less than $\alpha=0.05$.

These results conquer with Kimani (2015) that social media marketing has a lot of value to us because it allows employees to connect to the clients, especially the ones in different geographic zones. Social media allows firms to engage in timely and direct end-consumer contact at fairly low cost and higher levels of efficiency than can be achieved with more traditional communication tools. This makes social media not only relevant for large multinational firms, but also for small and medium sized companies, and even nonprofit and governmental agencies.

The results are also in line with Aden and Gichiga (2016) who examined the effect of customer care on organizational performance and found that service quality, customer satisfaction, customer relationship management, customer service delivery all have significant and positive effects on organizational performance. According to Kotler (2006) organizations are increasingly being customer centric and are embracing customer-driven initiatives that seek to understand, attract, retain and build intimate long term relationship with profitable customers. The results also agree with Hassan, and Ali, (2013) who investigated the relationship between customer service and organizational growth and found that there is appositive relationship between customer service and growth.

\section{SUMMARY OF THE FINDINGS, CONCLUSION AND RECOMMENDATIONS}

\section{A. Summary}

The study revealed a strong positive correlation coefficient between SMEs Performance in the international arena and customer relations such that a unit change in customer relations holding the other factors constant would lead to a great change in SMEs Performance in the International Arena. These findings concur with Franks and Curswoth, (2003) who found out that there is a strong positive correlation between customer relations and SMEs Performance. Further the study revealed that Social networking services used by SMEs operating in Kamukunji area focus on building online communities of people who share interests or activities or who are interested in exploring the interests and activities of others, Social applications enable the extension of relationships between a brand, product, or service to the individual level by providing very specific, member-selected functionality and that Social networking services employed by SMEs operating in Kamukunji area has the ability to impact the purchase decision cycle at all points

On sourcing for inputs, the study found strong positive correlation between SMEs Performance in the International Arena rate and sourcing for inputs, Test regression results revealed that a unit change in utilization of social media platforms in sourcing for inputs while holding the other factors constant would positively change SMEs Performance in the International Arena. These findings concur with the study findings by Njoroge (2011) who contents that in order to achieve the expected business performance outcomes; quality sourcing strategies must be available. This means that SMEs operating in Kamukunji were able to source for high quality materials through use of social media, and that social media networks facilitated effective sourcing of inputs even out of the country. These findings concur well with the study findings by Mangold and Faulds (2016) who found that Facebook enables companies to achieve a better understanding and consideration of customer needs hence build effective relationships. 


\section{B. Conclusions}

Based on the study findings, this study concludes that utilization of social media platform had a significant impact on fostering customer relations and ultimate performance in the International Arena. Likewise, social networking services employed by SMEs operating in Kamukunji area has the ability to impact the procurement decision cycle, enhance customer bonding activities and promote acquisition of new customers and retaining of the existing ones.

\section{Recommendations}

To promote SMEs performance in global arena, the study recommends that SMEs must invest in building stronger customer relationships especially through utilization of social media platforms. This can be managed through consistent customer follow-ups as well as engagements via social marketing platforms. SMEs therefore need to continually embrace the use of social media platforms in order to promote supplier relationship.

The study further recommends that utilization of social media platforms in sourcing for inputs should be embraced to enhance SMEs Performance in the International Arena. Social networking site that allows SMEs to have conversations with suppliers, post photos and videos, promote special offers, and more, 'micro-blogging' service that allows SMEs to send and receive short messages from supplies and potential bidders as well as social media online applications, platforms and media, should be enhanced to facilitate interaction, collaboration, and the sharing of content prices on input materials thus reducing acquisition cost and promotion of procurement efficiency.

\section{Recommendation for Further Studies}

The study investigated the role of social media networks on performance of Kamukunji SMEs in the International Arena. The study recommends that a similar research should be conducted with an aim of investigating role of social media in SMEs from other areas around Nairobi.

\section{REFERENCES}

Aden, B. \& Gichiga, M. (2016). Effectiveness of social media as a marketing tool: An empirical study. International Journal of Marketing, Financial Services \& Management Research, 1(11), 88-99.

Akeem, G. (2017). Business development services (BDS) in Ethiopia: Status, prospects and challenges in the micro and small enterprise sector. International Journal of Emerging Markets, 1(4), 305-328.

Altman, I. and Taylor, D.A. (1973) Social Penetration: The Development of Interpersonal Relationships. Holt, Rinehart, \& Winston, New York, 459

Blau, P. (2014). "Sustainability: UK retailers and social media". World Review of Entrepreneurship, Management and Sustainable Development, pp. 460-474.

Braskov, S. (2016). "A social media mindset". Journal of Interactive Advertising, pp. 1-3.

CBK (2017). Capital Raising Opportunities for SMEs: The Development of Micro-Cap Securities Markets in Kenya. Nairobi, Central Bank of Kenya.

Cooper, D. \& Schindler, P. (2011). Business research methods (7th ed.). Singapore: Mc Graw-Hill.

Douglas, E. (2016), "Empowering service employees", Sloan Management Review, Vol. 36 No. Summer, pp.73-84.

Eltantawy, S. \& Wiest, D. (2015). "The history of social media and its impact on business", Journal of Applied Management and Entrepreneurship. 79-91.

Emerson, D. (2014). Marketing orientation in SMEs: Effects on the internal environment. New England Journal of Entrepreneurship, 5(1), 13-22.
Eyrich, P. (2008). Enablers and inhibitors of advanced information technologies adoption by SMEs: An empirical study of auto ancillaries in India. Journal of Enterprise Information Management, 25(2), 186209

Franks, P. \& Curswoth, A. (2013). "A model of Internet adoption by SMEs." Information and Management, 39, 165-176.

Galbraith, J. \& Scendel, D. (2016). Social media marketing: the next generation of business engagement. John Wiley \& Sons.

Haenlein, M. (2016). The Challenges and Opportunities of Social Media. Business Horizon, 58-62.

Hassan, S. \& Ali, J. (2013)., Mobile Web 2.0 with multi-display buttons. Communications of the ACM. 2010. 53:1 pp 136-141

Icha, A., \& Agwu, M. (2015). Users of the world, unite! The challenges and opportunities of Social Media. Business Horizons. Business Horizons, $53,59-68$.

Jagongo, J. (2018). Towards Improving the Performance of Women Entrepreneurs in Small and Medium Enterprises in Nairobi County, Kenya: Policy Recommendations. International Journal of Business and Social Science. 4(9): 312-316.

Kabue, A. (2013). Factors Affecting the Performance of Small and Medium Enterprises in the Jua Kali Sector in Nairobi County, Kenya Egerton University.

Kanchanatanee, R. (2010). Networked narratives: Understanding word-ofmouth marketing in online communities. Journal of Marketing. 74. pp 71-89

Khan, A. \& Karodia, B. (2016). Business Linkages: Lessons, opportunities and Challenges. Cambridge, International Finance Corporation, International Business Leaders Forum and the Kennedy School of Government, Harvard University

Kilonzo, J. (2017). The Next Generation of Business Engagement. Canada: Wiley Publishing, Inc.

Kithae, P. Gakure, M. \& Munyao, L. (2012). The Place of Micro and Small Enterprises in Kenya in achievement of Kenya's Vision 2030. Journal of US-China Public Administration 9(12): 1432-1440.

Koroma, U. (2018). The Effectiveness of Social Media in Event Marketing. London: New Press.

Koroma, U. (2018). The Effectiveness of Social Media in Event Marketing. London: New Press.

Koshy, I. (2016). Social media and its impact on consumer's behavior. International Journal of Economic Practices and Theories, 4(2), 295303.

Kotler, M. (2006). "Users of the world, unite! The challenges and opportunities of Social Media". Business Horizons 53 (1): 59-68

Maina, E. (2016). Influence of Social Media Marketing on Performance of Telecommunication Firms in Kenya. International Journal of Innovative Research and Development 9(2):2-8

Mangold, D. \& Faulds, P. (2009). "An exploratory study of small business Internet commerce issues." Information and Management, 35, 9-18.

Mangold, G., \& Faulds, D. (2017). Social media. The new hybrid element of the promotion mix, 357-365.

Mangold, W. \& Faulds, D. (2009). "Social media: The new hybrid element of the promotion mix." Business Horizons 52: 357 - 365.

McGowan, C. \& McKeown, T. (2013). An Empirical Analysis of the Creation, Use and Adoption of Social Computing Applications. JRC Scientific and Technical Reports. Seville, Spain, Institute for Prospective Technological Studies: 92.

Moshabaki, S. (2013). Guerrilla Social Marketing. Canada: Entrepreneur Media Inc.

Mugenda, O. \& Mugenda, A. (2012). Research methods: Quantitative and qualitative approaches. Nairobi: Acts Press.

Ndlodo, C. \& Dhurup, F. (2015). To be or not to be in social media arena as the most cost-efficient marketing strategy after the global recession. Procedia Social and Behavioral Sciences, 24, 260-268.

Njoroge. O. (2011). Diffusion of ICTs and E-commerce adoption in manufacturing SMEs in Kenya. South African Journal of Libraries \& Information Science, 72(1).

Olonde, N. (2017). Entrepreneurs and entrepreneurship in Africa: What is known and what needs to be done. Journal of Developmental Entrepreneurship, 7(3).

Parveen, F. (2016) Social Media Playbook for Business, Reaching Your Online Community with Twitter, Facebook, Linkedln and More, pp.1-3

Robson, D. (2010). Social Media Marketing: An Hour a Day. Wiley Publishing.

Safko, N. \& Brake, V. (2016). Review: Information technology and organizational performance: an integrative model of IT business value. MIS Quarterly, 28(2), 283-322.

Stelzner, M. (2015). Technology Entrepreneurs Human Capital and its Effects on Innovation Radicalness, Entrepreneurship Theory and Practice, Bingley, UK: Emerald Group Publishing. 
Vij, P. \& James, P. (2014), "The Dynamics of SMEs Information Systems", Small Business Economics, Vol. 19, pp 1341-354.

Wanjiru, K. (2013). "PR practitioners' use of social media tools and communication technology." Public Relations Review Volume 24 Issue 4, pp. 412 - 414.

Werees, D. (2015). Inbound marketing: get found using Google, social media, and blogs (Vol. 1). John Wiley \& Sons Inc.

World Bank (2015). Doing Business 2014: Understanding Regulations for Small and Medium Size Enterprises. Washington, DC, World Bank Group.

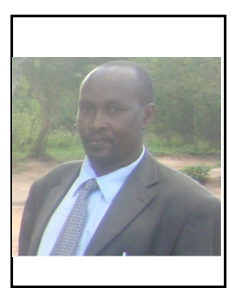

Peter Paul Kithae is currently the Director, Research, Development and Innovations of the Management University of Africa; the honorary treasurer for the Kenya Red Cross Society, Upper Eastern Kenya Region and a Senior Consultant with the Total Quality Management firm of Consultants. Among Dr. Kithae's published work include a Print book on "Technology adoption and its effect on performance of Youth-Led Micro and Small Enterprises, printed in June, 2015, a paper on the Extent the government has shaped MSE's destiny towards achievement of Kenya's vision 2030; A paper on the Effect of quality improvement practices on micro and small enterprise performance and another on Unleashing Potentiality of Our Youth through Entrepreneurship Training: A Must for Realization of Kenya's Vision 2030 among others. Dr Kithae is a career civil servant who has successfully worked as a Chief Youth Officer for three years and later as a Principal Youth Officer for two years in charge of Youth Development services in Makueni and Kirinyaga counties respectively. He has attended a lot of seminars and workshops and has facilitated a number of them. Among these are project planning and management, performance contracting, capacity assessment training and disaster preparedness and response. $\mathrm{He}$ is a renowned educationist, having been a senior Lecturer at the Management University of Africa for over three years, a part-time lecturer at the University of Nairobi, Embu Campus for four years and a lecturer of Entrepreneurship, management and Business Studies in various tertiary institutions for over 18 years. Dr Kithae has also been a Senior Examiner and Team leader for Business Studies with the Kenya National Examinations Council for over 10 years and a Senior Examiner for Research methods with the Kenya Institute of Management for over five years.

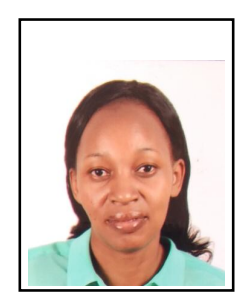

Judy Wanyoike works for the Government of Kenya, at the National Transport and Safety authority. She is a Management and Leadership student who is pursuing a master's degree program at the Management University of Africa 